\title{
Glucocorticoid-induced Impairment in Declarative Memory Performance in Adult Humans
}

\author{
J. W. Newcomer, ${ }^{1}$ S. Craft, ${ }^{2}$ T. Hershey, ${ }^{2}$ K. Askins, ${ }^{1}$ and M. E. Bardgett ${ }^{1,3}$ \\ Departments of ${ }^{1}$ Psychiatry and ${ }^{2} P$ sychology, Washington University, St. Louis, Missouri 63110, and the ${ }^{3}$ Department of \\ Psychology, University of Missouri-St. Louis, St. Louis, Missouri 63121
}

Glucocorticoids (GCs) have a variety of effects on the brain including site-preferential, inhibitory effects on hippocampal neurons. In the case of dexamethasone (DEX), extended rather than single-dose treatment in vivo may be required for binding to brain rather than peripheral (e.g., pituitary) GC receptors and for maximizing other biologic effects in hippocampus (e.g., GC receptor downregulation, inhibition of glucose transport). Based on the contributory role of hippocampal neurons in declarative memory performance, we investigated the cognitive consequences of DEX treatment in normal adult human subjects, hypothesizing a decrease in declarative memory performance after extended but not overnight treatment. Double-blind, placebo-controlled treatment with DEX was given at $2300 \mathrm{hr}$ for four consecutive days $(0.5,1,1,1 \mathrm{mg}$, respectively). Plasma sampling (0800 and $1600 \mathrm{hr}$ ) and cognitive testing ( $1600 \mathrm{hr}$ ) were performed on study days 0 (baseline), 1, and 4 , and $7 \mathrm{~d}$ posttreatment. Repeated-measures ANOVA found a significant interaction between study day and treatment condition for correct recall during a paragraph recall task $[F(3,51)=3.52, p=0.02]$. DEX $(n=10)$ in comparison to placebo $(n=9)$ treatment decreased correct paragraph recall on study day $4[F(1,17)$ $=5.01, p=0.04]$ and study day $11[F(1,17)=5.82, p=$ 0.03 ], with the lowest level of performance occurring on day 4 followed by a return toward baseline performance level by day 11. In the placebo-treated subjects, correct paragraph recall improved over the course of treatment, consistent with practice. No other cognitive measure was affected by DEX treatment, arguing against a nonspecific DEX effect on arousal or attention. Plasma cortisol concentrations were maximally suppressed at study day 4 , consistent with GC receptor binding by DEX.

[Key words: glucocorticoid, cognitive, memory, declarative memory, dexamethasone, cortisol, hippocampus]

Brief glucocorticoid (GC) exposure has been associated with a variety of physiologic and biochemical actions that can affect the brain, including the hippocampus. In some cases, site-pref-

\footnotetext{
Received May 10, 1993; revised Aug. 26, 1993; accepted Sept. 21, 1993.

This work was supported in part by National Institutes of Mental Health Grant MH01045 (J.W.N.), National Institutes of Aging Grant AG10880 (S.C.), Clinical Sciences Training Grant MH 14677 (M.E.B.), and U.S. Public Health Service Grant 5M01 RR00036. We thank Jacque Farrell and Amy E. Gagliardi for assistance with the manuscript and figures, respectively.

Correspondence should be addressed to John W. Newcomer, M.D., Department of Psychiatry, Washington University School of Medicine, 4940 Children's Place, St. Louis, MO 63110

Copyright (C) 1994 Society for Neuroscience $0270-6474 / 94 / 142047-07 \$ 05.00 / 0$
}

erential effects on hippocampal neurons versus neurons from other brain regions have been reported. Effects on hippocampal neurons include the site-preferential downregulation of hippocampal GC receptors (Sapolsky et al., 1984), involution of the dendritic processes of hippocampal neurons (Woolley et al., 1990), inhibition of long-term potentiation (Foy et al., 1987) and primed burst potentiation (Bennett et al., 1991; Diamond et al., 1992), and the site-preferential inhibition of glucose transport into hippocampal neurons and glia in a dose- and timedependent manner (Horner et al., 1990). The relatively higher density of GC receptors in the hippocampus, as compared with other CNS sites, may contribute to the site-preferential nature of some of these GC effects (Reul and de Kloet, 1985; Magarinos et al., 1989; IIorner et al., 1990). I Iowever, the interpretation of these reports is complicated by the varying sensitivity of different regions or subfields within the hippocampus to specific effects (e.g., McEwen et al., 1992). Further, relative binding to brain versus pituitary $\mathrm{GC}$ receptors in vivo has also been demonstrated to vary with the specific GC (e.g., synthetic vs endogenous), dose, and duration of treatment (Spencer et al., 1990; Miller et al., 1992).

A range of evidence supports the description in primates of a medial-temporal lobe declarative memory system that underlies the acquisition and recall of facts and events over short intervals (i.e., periods up to several weeks) (for review, see Squire and Zola-Morgan, 1991; Squire, 1992). This system is composed of the hippocampus, along with adjacent entorhinal, parahippocampal, and perirhinal cortices. The acute effect of GCs on memory performance in nonprimate species has been reported as both facilitating (Flood et al., 1978) and detrimental (Bohus and de Wied, 1980; Borrell et al., 1984). Early investigations also proposed a role for GCs and hippocampal GC receptors in the filtering of irrelevant stimuli by the hippocampus (McEwen, 1982). However, the implications of these nonprimate findings for human declarative memory performance are complicated by varying species, dose level and timing, and task characteristics. In addition, the wide distribution of $\mathrm{GC}$ receptors in brain and the complex genomic and nongenomic actions of GCs suggest that hippocampal or extrahippocampal effects could lead to a disruption of declarative memory or other cognitive functions.

Few controlled studies of GC effects on cognition in humans are available. In a naturalistic study design, Bender et al. (1991) reported decreased verbal memory performance during higherdose prednisone treatment of asthmatic children, as compared to lower doses. Investigators have also reported memory impairment (Mauri et al., 1993), as well as correlations between 
both plasma cortisol (CORT) and ACTH concentrations and memory performance, in patients with Cushing's disease (Starkman et al., 1986). In both investigations, cognitive improvement was associated with the reduction of plasma CORT concentiations. In a controlled experimental design using dexamethasone (DEX), prednisone, and placebo in normal adults and depressed patients, the administration of both GCs was linked to transient memory deficits (Wolkowitz et al., 1990). These deficits involved increased errors of commission, but not omission, during a word list recall task (i.c., incorrect recall of distracter words along with correct recall of target words).

To test the hypothesis that GCs have an effect on differentiated elements of cognitive functioning in humans, we prospectively investigated the cognitive consequences of DEX treatment in normal adults. A preferential decrease in declarative memory performance, in comparison to other elements of cognitive performance, was predicted during $4 \mathrm{~d}$ of DEX treatment. Based on (1) the time course of changes in $\mathrm{GC}$ receptor binding following GC exposure (Sapolsky et al., 1984), (2) the time course of GC-mediated changes in glucose transport (IIorner et al., 1990), and (3) the results of studies of GC receptor activation in the rat suggesting that extended, rather than overnight, 1reatment with DEX is required for binding to hippocampal, in contrast to pituitary, GC receptors (Spencer et al., 1990; Miller et al., 1992), we further hypothesized that a decrease in declarative memory performance would not be detectable until the fourth (vs the first) day of DEX treatment.

\section{Materials and Methods}

Cognitive testing and plasma sampling were performed before, during, and after a $4 \mathrm{~d}$ period of double-blind, placebo-controlled treatment with dexamethasone in normal adults $(n=19)$. On study days $0-3$ at $2300 \mathrm{hr}$, subjects reccived cither oral DEX $(n=10)$, in successive doses of $0.5,1,1$, and $1 \mathrm{mg}$, or matched placebo capsules $(n=9)$. Blood samples were obtained at 0800 and $1600 \mathrm{hr}$ on days 0 (baseline), 1, 4, and 11 ( $7 \mathrm{~d}$ recovery condition). Cognitive testing was performed immediately after the $1600 \mathrm{hr}$ blood drawing on study days 0 (baseline), 1,4 and 11 . All subjects in the experiment were evaluated for subjectively perceived adverse events at the completion of the protocol. A single subject dropped out of the protocol after the baseline assessment and first night of treatment complaining of adverse cognitive effects; this subject had been assigned to the placcbo condition and was not included in the analysis. One subject assigned to the DEX condition was unable to complete the day 11 assessment because of a family emergency; this subject denied any adverse events.

Subjects. All subjects gave written informed consent for their participation and were cmployecs or students from the Washington University Medical Center. Subjects werc evaluated in a clinical interview with a physician using Diagnostic and Statistical Manual of Mental Disorders, Third Edition, Revised (DSM-III-R; American Psychiatric Association, 1987) algorithms to make diagnoses. In order to avoid conditions associated with hypothalamic-pituitary-adrenal axis changes that could confound the results, subjects were excluded for any of the following: a lifetime history of a DSM-III-R psychiatric disorder (Axis I), including substance dependence or abuse; current pregnancy; any current medical illness, including trauma, fever, or dehydration in the past month; body weight $<80 \%$ ideal body weight; treatment with narcotics in the past month; and any treatment with corticosteroids, benzodiazepines, carbemazepine, other psychotherapeutic medications, or high-dose estrogens (in contrast to low-dose birth control treatment) (Carroll et al., 1981; Privitera et al., 1982; Swartz and Dunner, 1982; Ravi et al., 1981). Subjects were also excluded for any condition known to interfere with cognitive performance or contraindicate glucocorticoid use (e.g. neurological disorders, including any history of significant head injury, defined as a loss of consciousness for $\geq 5 \mathrm{~min}$ and/or with neurologic sequelae). In addition, subjects not routinely sleeping during nighttime hours were excluded from study, in an effort to standardize circadian cycles for all subjects. Handedness was measured for all subjects using a validated. normed inventory to determine a decile score (Oldfield. 1971 , in order to assess a potential confound to cognitive performance (Geschwind and Galaburda, 1987).

Cognitive assessments. A separate pilot experiment had been conducted in order to determine the performance effects of repeated testing with the cognitive battery. A separate set of 12 subjects (five females. seven males) was recruited from the Washington University campus. Subjects' mean age and mean number of years of education were 26.7 and 14.9 , respectively. Subjects were tested four times, on study days 0 (baseline), 1, 4, and 10. Although several measures showed a nonsignificant tendency toward improved performance over repeated testing (i.e., consistent with practice), a repeated-measures ANOVA found an ovcrall significant effect of study day for immediate paragraph recall only [mean bits recalled $1 \mathrm{SD}$ : day $0,10.4 \pm 3.2$; day $1,9.1+2.4$; day 4. $9.7 \pm 3.3$ : day $10,13.2 \pm 5.8 ; F(3,9)=4.62, p<0.05]$. Post-hoc comparison revealed a significant improvement between day 4 and day $10[F(1,11)=7.89, p<0.05]$, with no differences noted between other test days.

In the present experiment on study days 0 (baseline), 1,4 , and 11 at $1600 \mathrm{hr}$, subjects were administered a $35 \mathrm{~min}$ cognitive battery that measured verbal declarative memory performance, attention, vigilance, and visuoperceptual function. These measures were selected to provide a standardized assessment of verbal declarative memory performance with controls for attention, arousal level, and visual spatial function. A different version of the battery was administered on each of the 4 test days. Two alternate sets of the four-version battery were available (i.e., eight versions in total); subjects were randomly assigned to testing with one or the other set in order to prevent any response bias (e.g., to particular paragraph content) from affecting the results. Analysis revealed no differences in overall performance on the two versions of the battery. Testing was performed by a single trained rater (K.A.), blind to the treatment assignment (i.e., DEX vs placebo) of individual subjects. The cognitive measures included in both the pilot and the current experiment are outlined below.

(1) The paragraph recall test (Wechsler, 1945) is a validated (Squire, 1987) and sensitive measure (Butters et al., 1978; Storandt et al., 1984) of verbal declarative memory performance. Although performance on this task is also dependent on other cognitive ahilities such as intact organizational and learning strategies, and the functioning of some other brain structures, paragraph recall performance has been strongly related to the integrity of the medial-temporal lobe declarative memory system that includes hippocampus (Squirc, 1992). Subjects hear a recorded short narrative with 25 bits of information, modeled on the Wechsler Memory Scale-Revised Logical Memory Test (Wechsler, 1987), followed by immediate and delayed $(0.5 \mathrm{hr})$ verbatim recall. Twenty paragraphs of approximately equal length were constructed using a previously established method (Wechsler, 1987). One paragraph was given at each test session; scores for correct recall were tabulated using established scoring methods (Russell, 1975; Gangarosa et al., 1988). Total scores for (1) correct verbatim recall of paragraph bits as well as (2) commission errors (combining both intrusions and perseverations into a single summed score) were tahulated for hoth the immediate and delayed recall condition.

(2) A serial addition task was used as one measure of attention. The task (Gronwall and Wrightson, 1974) involves standardized audiotape presentation of a set of number strings where subjects are asked to calculate the sum of each string. Each string begins with a number from 11010 , followed by a sequence of 10 ones and twos. Five series of two strings each are presented, using $4,3,2,1.5$, and 1 sec intervals between numbers, respectively. Errors were recorded for use in the analysis. This test requires an ability to add as well as attention and mental control over the duration of the test.

(3) The second attentional measure, the vigilance task, requires sustained attention and working knowledge of the alphabet (Weintraub and Mesulam, 1985) and involves a standardized audiotape presentation of a random series of letters, at a rate of one letter per second. Starting with an initial practice series, subjects are asked to identify (i.e., signal acknowledgement of) the letters of the alphabet, in sequence, as each one is heard during the random series of letters. In the abbreviated practice series, for example, the subject might hear the sequence B-NA-Q-B-K-C, where they should correctly signal (c.g., raise their finger) at the first occurrence of the letter $A$ (third letter), then the first occurrence of the letter $B$ (fifth letter), then the first occurrence of the letter $\mathrm{C}$ (seventh letter), and so on if the series were longer. An error score, consisting of omissions, false positives, and late signals (two or more letters after the target) was constructed for use in the analysis. 


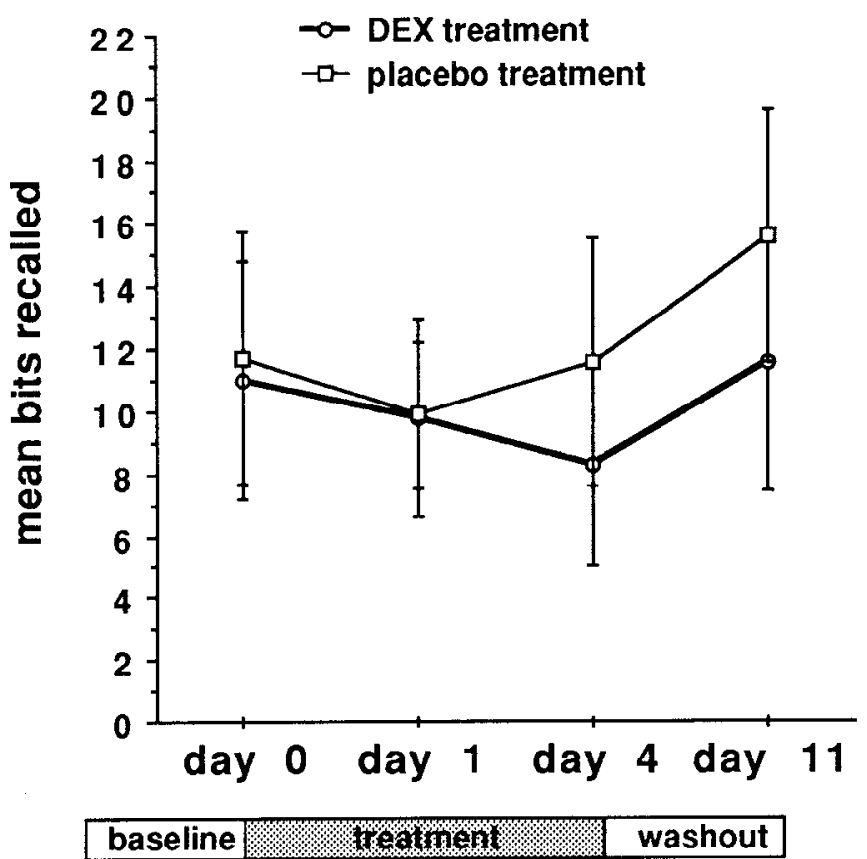

Figure 1. Mean immediate paragraph recall scores ( $\pm \mathrm{SD})$ during treatment wilh $\operatorname{DEX}(n=10)$ or placebo $(n-9)$.

(4) The integrity of visuoperceptual function was assessed using the Benton line orientation task (Benton et al., 1983). Subjects are first shown a template of 11 numbered lines of different orientations. Subsequent pictures, each consisting of two of these lines without numbers, are presented with the template for correct identification of the number that should accompany each line. Each test has five sets of unnumbered lines with errors scored as the number of incorrectly identified lines.

$D E X$ and CORT measurement. Plasma was immediately separated from whole blood by centrifugation and stored at $-80^{\circ} \mathrm{C}$ prior to assay. CORT concentrations were measured by radioimmunoassay using a commercial kit from ICN Bionedicals (Costa Mesa, CA). For the measurement of plasma DEX concentrations, the radioimmunoassay protocol described by Ritchie et al. (1990) was employed using an antiserum ( $\operatorname{lgG}$-dexamethasone-1) supplied by $\lg G$ Corporation (Nashville, TN) and a tracer $\left(1,2,4,6,7-{ }^{3} \mathrm{H}\right.$-DEX) supplied by New England Nuclear (Boston, MA). The separation buffer contained a $16 \mathrm{mg} / 100 \mathrm{ml}$ concentration of silica gel to enhance the separation of bound from unbound ligand. After addition of separation buffer to each tube, tubes were centrifuged at $3000 \times g$ at $4^{\circ} \mathrm{C}$ for $20 \mathrm{~min}$.

Analysis. The effects of DEX and placebo treatment on cognitive performance were assessed using repeated-measures ANOVA to evaluate the overall effect of study day for specific cognitive measures comparing both treatment conditions (i.e., DEX vs placebo treatment). The following cognitive variables were tested: paragraph bits correctly recalled in the immediate and delayed recall condition, commission errors in the immediate and delayed recall condition, errors in the serial addition task, errors in the vigilance task, and errors in the line orientation task. Because the paragraph recall task includes both an immediate and a delayed recall condition where performance is to some degree related across conditions, three-way, repeated-measures ANOVA (recall condition $\times$ treatment condition $\times$ study day) was used to test empirically for separable effects of treatment on the immediate versus delayed measures of both correct recall performance and commission errors. The other cognitive measures were evaluated using two-way, repeated-measures ANOVA (treatment condition $\times$ study day). A comparison of cognitive performance during DEX versus placebo treatment on each separate study day (e.g., paired ANOVA comparing vigilance errors across treatment condition for each study day) was also planned as warranted by the results of the initial ANOVA, in order to test for the hypothesized time course for the DEX effect (i.e., detectable at study day 4). A critical value of $p=0.05$ was used in evaluating all comparisons. The comparability of the DEX-versus placebo-treated groups was assessed using unpaired $t$ test comparisons among the demographic

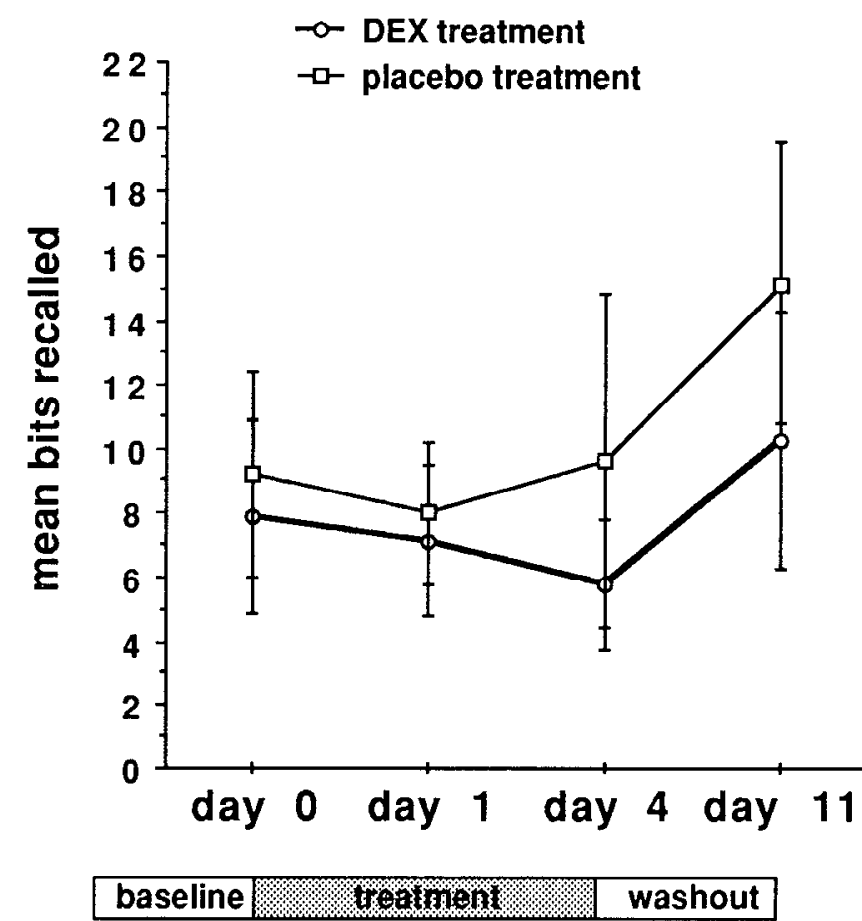

Figure 2. Mean delayed paragraph recall scores ( \pm SD) during treatment with $\operatorname{DEX}(n=10)$ or placebo $(n=9)$.

variables (e.g., age, number of years of education). Finally, possible confounds to the primary analysis, such as the effect of age, and plasma CORT or DEX levels, were explored using Spearman's correlation estimates between specific measures of interest.

\section{Results}

Age of subjects, number of years of education, and handedness scores did not differ significantly between the DEX- and placebo-treated groups [mean $\pm \mathrm{SD}$ : age $(t=1.96), 38.3 \pm 10.2$ vs $29.4 \pm 9.4$; years of schooling $(t=0.54), 16.5 \pm 1.4$ vs 15.9 \pm 3.3 ; handedness score $(t-0.08), 3.3 \pm 4.0$ vs $3.1 \pm 5.4$, respectively]. The ratio of males to females in the DEX- and placebo-treated groups (4:6 and 4:5, respectively) was also comparable. Repeated-measures ANOVA revealed a significant interaction between treatment condition and study day $[F(3,51)$ $=3.52, p=0.02]$ for correct recall during the paragraph recall task. Mean correct scores for immediate and delayed recall, comparing DEX and placebo treatment, are shown in Figures 1 and 2. No significant interactions were found in the ANOVA evaluating commission errors in the paragraph recall task, or in the ANOVAs evaluating error scores for any other cognitive task, consistent with no significant overall effect of treatment on cognitive performance for any of these measures.

DEX, and not placebo, treatment resulted in a parallel decrease in both the immediate and delayed measure of correct paragraph recall, followed by posttreatment recovery to baseline levels. No significant interactions were found between recall condition (immediate vs delayed) and either treatment condition or study day (two-way interactions). Further, no significant interaction was found among recall condition, treatment condition, and study day (three-way interaction), consistent with no significant separable effect of treatment on correct recall performance across the recall conditions. Consequently, immediate and delayed correct recall scores were collapsed (by summing the scores for immediate and delayed bits recalled) into a single 
overall correct recall score for use in the next part of the analysis. Paired ANOVA comparing this overall correct recall measure during DEX versus placebo treatment for each study day found a significant difference between treatment conditions on study day $4[F(1,17)=5.01, p=0.04]$ and study day $11[H(1,17)=$ $5.82, p=0.03]$ only. These differences are consistent with the hypothesized time for detection of the DEX effect and with an extended decrement in recall performance following DEX treatment. When asked about subjectively perceived adverse events at the completion of the experiment, no subject reported any cognitive, psychological. or other effects.

Plasma CORT concentrations in the DEX-treated subjects were maximally suppressed at study day 4 , consistent with $\mathrm{GC}$ receptor binding by DEX. The mean plasma DEX concentration value approximately doubled from study day 1 to study day 4; these values were within or just above, respectively, the previously reported range obtained in humans at $0800 \mathrm{hr}$ after a single $1 \mathrm{mg}$ DEX dose at $2300 \mathrm{hr}$ (Lowy and Melizer, 1987). In the total study sample, plasma CORT concentrations were significantly correlated with immediate $\left(r_{s}=0.48, p<0.05\right)$ and delayed $\left(r_{s}=0.48, p<0.05\right)$ recall performance on study day 4 and delayed recall performance $\left(r_{s}=0.60, p<0.05\right)$ on study day 11 , reflecting higher plasma CORT concentrations and recall scores in subjects taking placebo; no similar relationships were found in the DEX-treated subjects alone (i.e., where the decreases in memory performance were found). No other relationships between plasma CORT concentrations and other measures of cognitive performance on any study day were found in the total study sample or DEX-treated subjects.

An inverse relationship was found between age and baseline $0800\left(r_{s}=-0.78, p<0.001\right)$ and $1800 \mathrm{hr}\left(r_{\mathrm{s}}=-0.51, p<\right.$ $0.05)$ plasma CORT concentrations in the total sample. Age, number of years of education, and handedness scores were generally unrelated to cognitive performance in the total sample, although baseline error scores on the line orientation task were corrclated with age $\left(r_{s}=0.53, p<0.05\right)$, and baseline immediate recall performance was related to the number of years of education $\left(r_{s}=0.51, p<0.05\right)$. No significant effects of subject gender were found. Although the sample size for the DEXtreated subjects was small, an exploratory inspection of the data found no strong relationships between plasma DEX concentrations and cognitive performance on any study day, a moderately strong negative relationship botween subjects' age and day 1 . post-DEX CORT concentrations at $1800 \mathrm{hr}$ only $\left(r_{s}=-0.74\right.$, $p<0.05$ ), and no relationship between age and plasma DEX concentrations or between age and cognitive performance during DEX treatment.

\section{Discussion}

The results of this investigation suggest an impairment of verbal declarative memory performance in normal adult human subjects after relatively low-dose and brief DEX treatment. The performance deficits found on the paragraph recall task do not appear to reflect a gencralized deficit in attention or arousal. Although performance on this memory task is also dependent on other cognitive functions such as intact organizational and learning capacitics, earlier investigations have strongly related paragraph recall performance to the integrity of the medialtemporal lobe declarative memory system that includes hippocampus (for review, see Squire, 1992). However, this investigation did not assess some other aspects of higher cognitive function (e.g., procedural memory), leaving the selectivity of the
DEX effect for declarative memory performance uncertain. The results strengthen previous evidence of a GC-mediated memory deficit in humans, reported during DEX and prednisone treatment (Wolkowitz et al., 1990; Bender et al., 1991) and in relation to plasma CORT concentration in patients with Cushing's disease (Starkman et al., 1986).

Wolkowitz et al. (1990) had previously reported GC treatment-rclated errors of commission during a word list recall task. The present experiment found omission but not commission errors during DEX treatment. Both commission and omission errors have been associated with hippocampal and medial-temporal memory system dysfunction (Squire, 1987; Crosson et al., 1993). The use of young normal subjects in the present experiment (minimizing the incidence of commission errors) as well as differences between the word list and paragraph recall tasks (Lezak. 1983) may account for the differences in results. Future studies should attempt to clarify the effect of GC treatment on errors of omission versus commission using subjects of varying age and more than one measure of performance.

While the sample size for this experiment was small, outliers did not explain the findings; the delayed recall data for individual subjects, comparing study days 1 and 4. showed decreasing performance for 7 of the 10 subjects receiving DEX. However, no clinical (e.g., gender) or plasma measure (e.g., DEX concentration) was related to cognitive outcome in the secondary analyses of the smaller sample receiving DEX, and a type II crror could have occurred. In addition, the baseline error rate for the nonmemory tasks in the present experiment was low, suggesting that the tasks could have been overlearned and less sensitive to detrimental effects. Future studies should address the specificity of the GC effect on declarative memory in contrast to nondeclarative memory performance (e.g., priming) or nonmemory elements of cognitive performance using additional memory tasks and more complex nonmemory measures. Given the wide distribution of $\mathrm{GC}$ receptors in brain and the complex genomic and nongenomic actions of $G C s$, it is possible that either hippocampal or extrahippocampal effects could lead to a disruption of declarative memory performance. The underlying hypothesis that GC treatment may preferentially affect the functioning of hippocampus versus other brain regions remains to be tested by direct measures of neuronal function.

In the placebo-treated subjects, paragraph recall performance improved over the course of treatment, consistent with a practice effect. In contrast, DEX-treated subjects did not show an overall improvement in paragraph recall petformance during the trial. This difference may reflect either (1) a prolonged effect of DEX on declarative memory performance (e.g., see Table 1; note that DEX concentrations were still detectable on study day 11). (2) a DEX-induced impairment in procedural memory that retarded task learning, such that treated subjects were slower than controls in manifesting practice-related improvement, or (3) less of a final test session improvement in the DEX-1reated group due to less proactive interference during the earlier test sessions in this group (see below). The improvement in paragraph recall performance in the placebo-treated subjects was most notable between study days 4 and 11 , and may have been due to the relatively longer interval between test sessions resulting in a release from the deleterious effect of proactive interference caused by recent cognitive testing (Craik, 1977). Proactive interference tends to be associated with better memory performance (i.e., better recall from test session to test session leads to more potential interference from previously pre- 


\begin{tabular}{|c|c|c|c|c|}
\hline \multirow[b]{2}{*}{ Variable } & \multicolumn{4}{|l|}{ DEX/placebo } \\
\hline & Day 0 & Day 1 & Day 4 & Day 11 \\
\hline \multirow{2}{*}{$\begin{array}{l}\text { Immediate recall } \\
\text { commission errors }\end{array}$} & $0.8 \pm 1.5$ & $1.3 \pm 1.8$ & $0.9 \pm 0.7$ & $0.4 \pm 0.5$ \\
\hline & $0.9 \pm 0.9$ & $0.8 \pm 1.3$ & $0.8 \pm 1.1$ & $1.1 \pm 1.1$ \\
\hline \multirow{2}{*}{$\begin{array}{l}\text { Delayed recall } \\
\text { commission errors }\end{array}$} & $1.7 \pm 1.4$ & $1.8 \pm 2.3$ & $1.2 \pm 0.9$ & $0.6 \pm 0.7$ \\
\hline & $1.1 \pm 1.1$ & $1.2 \pm 1.3$ & $1.1 \pm 1.1$ & $1.4 \pm 1.0$ \\
\hline \multirow[t]{2}{*}{ Serial addition errors } & $0.6 \pm 1.1$ & $0.8 \pm 1.2$ & $0.4 \pm 0.7$ & $0.4 \pm 0.5$ \\
\hline & $1.4 \pm 1.5$ & $0.8 \pm 1.1$ & $1.3 \pm 1.5$ & $0.3 \pm 0.5$ \\
\hline \multirow[t]{2}{*}{ Vigilance errors } & $1.0 \pm 0.8$ & $0.4 \pm 0.8$ & $0.5 \pm 0.7$ & $0.2 \pm 0.4$ \\
\hline & $0.7 \pm 0.7$ & $0.8 \pm 0.8$ & $0.4 \pm 0.7$ & $0.4 \pm 0.7$ \\
\hline \multirow{2}{*}{$\begin{array}{l}\text { Line orientation } \\
\text { errors }\end{array}$} & $1.5 \pm 2.1$ & $0.9 \pm 0.7$ & $1.5 \pm 2.0$ & $0.3 \pm 0.5$ \\
\hline & $0.8 \pm 0.7$ & $0.9 \pm 0.6$ & $0.9 \pm 0.6$ & $0.7 \pm 0.7$ \\
\hline \multirow{2}{*}{$\begin{array}{l}{[\mathrm{CORT}] 0800 \mathrm{hr}(\mu \mathrm{g} /} \\
\quad \mathrm{dl})\end{array}$} & $16.3 \pm 6.2$ & $3.6 \pm 4.0$ & $0.1 \pm 0.4$ & $18.5 \pm 12.8$ \\
\hline & $30.7 \pm 14.8$ & $28.8 \pm 18.6$ & $27.5 \pm 15.6$ & $29.3 \pm 17.1$ \\
\hline $\begin{array}{l}{[\mathrm{DEX}] 0800 \mathrm{hr}(\mathrm{ng} /} \\
\mathrm{ml})\end{array}$ & & $2.5 \pm 0.9$ & $4.7 \pm 1.6$ & $0.3 \pm 0.2$ \\
\hline
\end{tabular}

sented material), and would be expected to be greater in the placebo-treated subjects in this experiment. Similarly, the improvement in performance that should accompany the release from proactive interference would also be expected to be greater in the placebo-treated subjects.

It is also possible that DEX itself was not directly responsible for the cognitive effect but acted to lower plasma CORT concentrations. Reduced CORT concentrations in brain might be hypothesized to explain directly the cognitive effect. Although this idea may be weakened by the data from patients with Cushing's disease (Starkman et al., 1986; Mauri et al., 1993), the CORT-based hypothesis is supported by reports that DEX does not readily enter the brain and suppresses CORT at the level of the pituitary following overnight treatment (e.g., Miller et al., 1992). However, longer treatment with DEX was not a part of this or other studies reporting this conclusion. In contrast, another GC receptor activation study suggests that extended ( 1 , 2 , and $3 \mathrm{~d}$ ), rather than overnight, in vivo treatment with DEX is required for binding to hippocampal rather than peripheral GC receptors (Spencer et al., 1990). Entry of DEX into brain at these doses (selected to produce plasma concentrations in the range seen in humans following overnight $1 \mathrm{mg}$ treatment) is notably time dependent.

Consistent with the time course for DEX entry into the rat brain during similar treatment, the effect on recall performance in humans was detectable after DEX treatment for $4 \mathrm{~d}$ but not overnight. In contrast, plasma CORT concentrations were markedly suppressed by the overnight treatment with $0.5 \mathrm{mg}$ of DEX and had returned to baseline levels by day 11 (see Table 1), suggesting a temporal dissociation between effects on plasma CORT concentration and cognitive function. Consistent with the time course for the decrease in recall performance, the mean plasma DEX concentration value approximately doubled from study day 1 to study day 4 (the mean value at day 4 was just above the previously reported range obtained in humans at 0800 $\mathrm{hr}$ after a single $1 \mathrm{mg}$ DEX dose at $2300 \mathrm{hr}$ ) (Lowy and Meltzer, 1987). In sum, (1) the present experiment should have offered sufficient treatment time for DEX binding to brain (e.g., hippocampus), and (2) changes in plasma DEX, rather than plasma CORT, concentration appear to be more temporally consistent with the cognitive effect. However, further experiments are obviously required to better determine the relationship of DEX versus CORT to cognitive function (see below). The plasma DEX measurements did provide evidence for subject compliance with self-administered DEX doses.

This investigation was limited by the use of DEX as the only steroid treatment; other steroid hormones (i.e., CORT, progesterone, testosterone) could have had similar effects on memory performance. However, precursors for both androgenic and estrogenic steroids (Flood et al., 1992) as well as estrogenic steroids themselves (Phillips and Sherwin, 1992) have been reported to have enhancing effects on memory performance. Both DEX and prednisone produced the same detrimental effect in the word list recall paradigm used by Wolkowitz et al. (1990), although differences in the effect of different GCs on memory performance have been found in animal experiments (Micco and McEwen, 1980; Bohus and de Kloet, 1981). The constant DEX dose following the first study day prevented a dose-response relationship from being explored and limited the variance in plasma DEX concentrations in this experiment. However, plasma CORT concentrations, an index of DEX activity, were correlated with day 4 memory performance across the total subject sample (i.e., subjects receiving both DEX and placebo); this is consistent with the lower CORT levels and memory scores found in the DEX-treated group (no similar relationship was found in the DEX-treated subjects alone).

The exploratory analyses found an inverse relationship between subjects" age and day $11800 \mathrm{hr}$ post-DEX CORT concentrations, suggesting increased plasma DEX concentrations in older subjects. Although previous investigators have reported a direct correlation between age and plasma CORT concentrations (Oxenkrug et al., 1983), the small sample size of DEXtreated subjects, the generally younger age of the subjects, and the doses of DEX used in this investigation may explain this discrepancy. This experiment did not measure $\mathrm{ACl} H$ and related secretagogues that may be altered by DEX treatment and may affect memory performance (McGaugh, 1983). The dircction of the ACTH-related cognitive effect appears to be dependent on dose and the specific cognitive paradigm (Gold and Delanoy, 1981). Finally, potential confounds to the interpre- 
tation of the primary analysis were not found in the correlational analyses of any relevant variables.

The neurobiological mechanism underlying the impairment in delayed recall performance during DEX treatment in humans remains to be studied. From a "hypothesis-generating" perspective, this declarative memory deficit is consistent with a preferential GC effect on hippocampal neurons. However, nonhippocampal effects or a secondary effect of reduced CORT cannot be excluded. Future investigations should address the specificity of the findings with an expanded cognitive battery, along with different steroids and variables doses, including stressphysiologic doses of CORT. If a deleterious effect of CORT on declarative memory performance were confirmed, this would suggest the possibility of a causal component in the previously reported associations between plasma CORT concentrations and memory impairment in a variety of neuropsychiatric diseases such as Cushing's disease (Whelan et al., 1980; Starkman et al., 1986), Alzheimer's disease (Jenike and Albert, 1984), schizophrenia (Newcomer et al., 1991), and depression (see Reus, 1984, for revicw).

\section{References}

American Psychiatric Association (1987) Diagnostic and statistical manual of mental disorders, $3 \mathrm{~d}$ ed, revised. Washington, DC: American Psychiatric Association.

Bender BG, Lerner JA, Poland JE (1991) Association between corticosteroids and psychologic change in hospitalized asthmatic children. Ann Allergy 66:414-419.

Bennett MC, Diamond DM, Fleshner M, Rose GM (1991) Serum corticosterone level predicts the magnitude of hippocampal primed burst potentiation and depression in urethane-anesthetized rats. Psychobiology 19:301-307.

Benton AI, Hamsher K, Varney NR, Spreen O (1983) Contributions to neuropsychological assessment. New York: Oxford UP.

Bohus B, de Kloet ER (1981) Adrenal steroids and extinction behavior: antagonism by progesterone, deoxycorticosterone and dexamethasone of a specific effect of corticosterone. Life Sci 28:433-440.

Bohus B, de Wied D (1980) Pituitary-adrenal system hormones and adaptive behavior. In: General comparative and clinical endocrinology of the adrenal cortex (Jones IG, Henderson IW, eds), pp 265347. London: Academic.

Borrell J, de Kloet EK, Bohus B (1984) Corticosterone decreases the efficacy of adrenaline to affect passive avoidance retention of adrenalectomized rats. Life Sci 34:99-105.

Butters N, Sax D, Montgomery K, Tarlow S (1978) Comparison of the neuropsychological deficits associated with early and advanced Huntington's disease. Arch Neurol 35:585-589.

Carroll BJ, Feinberg M, Greden JF, Tarika J, Albala AA, Haskett RF, James NM, Kronfol Z, Lohr N, Steiner M, de Vigne JP, Young E (1981) A specific laboratory test for the diagnosis of melancholia. Arch Gen Psychiatry 38:15-22.

Craik FIM (1977) Age differences in human memory. In: Handbook of the psychology of aging (Birren JE, Schaie KW, eds), pp 384-420. New York: Von Nostrand Reinhold.

Crosson B, Sartor KJ, Jenny AB III, Nabors NA, Moberg PJ (1993) Increased intrusions during verbal recall in traumatic and nontraumatic lesions of the temporal lobe. Neuropsychology 7:193-208.

Diamond DM, Bennett MC, Fleshner M, Rose GM (1992) Inverted-U relationship between the level of peripheral corticosterone and the magnitude of hippocampal primed burst potentiation. Hippocampus $2: 421-430$.

Flood JF, Vidal D, Bennett EL, Orme AE, Vasquez S, Jarvik ME (1978) Memory facilitating and anti-amnesic effects of corticosteroids. Pharmacol Biochem Behav 8:81-87.

Flood JF, Morley JE, Roberts E (1992) Memory-enhancing effects in male mice of pregnenolone and steroids metabolically derived from it. Neurobiology 89:1567-1571.

Foy MR, Stanton ME, Levine S, Thompson RF (1987) Behavioral stress impairs long-term potentiation in rodent hippocampus. Behav Neural Biol 48:138-149.
Gangarosa ME, Saykin AJ, Malamut BL, Gur RC (1988) New scoring systems for Wechsler Memory Scale: inter-rater reliability. J Clin Exp Neuropsychol 10:1-43.

Geschwind N, Galaburda AM (1987) Cerebral lateralization-biological mechanisms, associations, and pathology. Cambridge, MA: MIT Press.

Gold PE, Delanoy RL (1981) ACTH modulation of memory storage processing. In: Endogenous peptides and learning and memory processes (Martinez JC Jr, Jensen RA, Messing RB, Rigter H, McGaugh JL, eds), pp 79-98. New York: Academic.

Gronwall D, Wrightson P (1974) Recovery after minor head injury. Lancet II: 1452.

Horner HC, Packan DR, Sapolsky RM (1990) Glucocorticoids inhibit glucose transport in cultured hippocampal neurons and glia. Neuroendocrinology 52:57-64.

Jenike MA, Albert MS (1984) The dexamethasone suppression test in patients with presenile and senile dementia of the Alzheimer's type. J Am Geriatr Soc 32:44 1-444.

Lezak MD (1983) Neuropsychological assessment. New York: Oxford UP.

Lowy MT, Meltzer HY (1987) Dexamethasone bioavailability: implications for DST research. Biol Psychiatry 22:373-385.

Magarinos AM, Ferrini M, De Nicola AF (1989) Corticosteroid receptors and glucocorticoid content in microdissected brain regions: correlative aspects. Neuroendocrinology 50:673-678.

Mauri M, Sinforiani E, Bono G, Vignati F, Berselli ME, Attanasio R, Nappi G (1993) Memory impairment in Cushing's disease. Acta Neurol Scand 87:52-55.

McEwen BS (1982) Glucocorticoids and hippocampus: receptors in search of a function. In: Current topics in neuroendocrinology, Vol 2, Adrenal actions on brain (Ganten D, Pfaff D, eds), pp 1-22. New York: Springer.

McEwen BS, Angulo J, Cameron H, Chao HM, Daniels D, Gannon MN, Gould E, Mendelson S, Sakai R, Spencer R, Woolley C (1992) Paradoxical effects of adrenal steroids on the brain: protection versus degeneration. Biol Psychiatry 31:177-199.

McGaugh JL (1983) Hormonal influences on memory. Annu Rev Psychol 34:297-323.

Micco DJ Jr, McEwen BS (1980) Glucocorticoids, the hippocampus, and behavior: interactive relation between task activation and steroid hormone binding specificity. J Comp Physiol Psychol 94:624-633.

Miller AH, Spencer RL, Pulera M, Kang S, McEwen BS, Stein M (1992) Adrenal steroid receptor activation in rat brain and pituitary following dexamethasone: implications for the dexamethasone suppression test. Biol Psychiatry 32:850-869.

Newcomer JW, Faustman WO, Whiteford HA, Moses JA Jr, Csernansky JG (1991) Symptomatology and cognitive impairment associate independently with post-dexamethasone cortisol concentrations in unmedicated schizophrenic patients. Biol Psychiatry 29:855-864.

Oldfield RC (1971) The assessment and analysis of handedness: the Edinburgh inventory. Neuropsychologia 9:97-113.

Oxenkrug GF, Pomara N, McIntyre IM, Branconnier RJ, Stanley M, Gershon S (1983) Aging and cortisol resistance to suppression by dexamethasone: a positive correlation. Psychiatry Res 10:125-130.

Phillips SM, Sherwin BB (1992) Effects of estrogen on memory function in surgically menopausal women. Psychoneuroendocrinology 17: 485-495.

Privitera MR, Greden JF, Gardner RW, Ritchie JC, Carroll BJ (1982) Interference by carbamazepine with the Dexamethasone Suppression Test. Biol Psychiatry 17:611-620.

Ravi SD, Dorus W, Park YN, Collins MC, Reid RW, Borge GF (1984) The Dexamethasone Suppression Test and depressive symptoms in early and late withdrawal from alcohol. Am J Psychiatry 141:14451448.

Reul JMHM, de Kloet ER (1985) Two receptor systems for corticosterone in rat brain: microdistribution and differential occupation. Endocrinology 117:2505-2511.

Reus VI (1984) Hormonal mediation of the memory disorder in depression. Drug Dev Res 4:489-500.

Ritchie JC, Belkin BM, Krishnan RR, Nemeroff CB, Carroll BJ (1990) Plasma dexamethasone concentrations and the Dexamethasone Suppression Test. Biol Psychiatry 27:159-173.

Russell EW (1975) A multiple scoring method for assessment of complex memory functions. J Consult Clin Psychol 43:800-809.

Sapolsky RM, Krey LC, McEwen BS (1984) Stress down-regulates 
corticosterone receptors in a site-specific manner in the brain. Endocrinology 114:287-292.

Spencer RL, Young EA, Choo PH, McEwen BS (1990) Adrenal steroid type I and type II receptor binding: estimates of in vivo receptor number, occupancy, and activation with varying levels of steroid. Brain Res 514:37-48.

Squire LR (1987) Memory and brain. New York: Oxford UP.

Squire LR (1992) Memory and the hippocampus. A synthesis from findings with rats, monkeys, and humans. Psychol Rev 99:195-231.

Squire IR, 7ola-Morgan $S$ (1991) The medial temporal lobe memory system. Science 253:1380-1386.

Starkman MN, Schteingart DE, Schork MA (1986) Cushing's syndrome after treatment: changes in cortisol and ACTH levels, and amelioration of the depressive syndrome. Psychiatry Res 19:177-188.

Storandt M, Botwinick J, Danziger WL, Berg L, Hughes CP (1984) Psychometric differentiation of mild senile dementia of the Alzheimer type. Arch Neurol 41:497-499.

Swartz CM, Dunner FJ (1982) Dexamethasone suppression testing of alcoholics. Arch Gen Psychiatry 39:1309-1312.
Wechsler D (1945) A standardized memory scale for clinical use. J Psychol 19:87-95.

Wechsler D (1987) Wechsler memory scale-revised. New York: Harcourt Brace Jovanovich.

Weintraub S, Mesulam MM (1985) Mental state assessment of young and elderly adults in behavioral neurology. In: Principles of behavioral neurology (Mesulam M, ed), pp 71-115. Philadelphia: Davis.

Whelan TB, Schteingart DE, Starkman MN, Smith A (1980) Neuropsychological deficits in Cushing's syndrome. J Nerv Ment Dis 168: 753-757.

Wolkowitz OM, Reus VI, Weingartner H, Thompson K, Breier A, Doran A, Rubinow D, Pickar D (1990) Cognitive effects of corticosteroids in man. Am J Psychiatry 147:1297-1303.

Woolley CS, Gould E, McEwen BS (1990) Exposure to excess glucocorticoids alters dendritic morphology of adult hippocampal pyramidal neurons. Brain Res 531:225-231. 